\title{
Urinary Vascular Endothelial Growth Factor (VEGF) as a Novel Marker for Early Prediction of Esophageal Varices in Patients with Chronic Liver Disease
}

\author{
Yasser Bakr Mohamed1', Ula M. Al-Jarhi', Mona Mohsen², Sarah Ahmad El Morsy³ \\ ${ }^{1}$ Department of Medicine, Cairo University, Cairo, Egypt \\ ${ }^{2}$ Department of Chemical Pathology, Cairo University, Cairo, Egypt \\ ${ }^{3}$ Mataria Hospital, Cairo, Egypt \\ Email: ulamabid.aljarhi@gmail.com
}

How to cite this paper: Mohamed, Y.B., Al-Jarhi, U.M., Mohsen, M. and El Morsy, S.A. (2017) Urinary Vascular Endothelial Growth Factor (VEGF) as a Novel Marker for Early Prediction of Esophageal Varices in Patients with Chronic Liver Disease. Open Journal of Gastroenterology, 7, 141153.

https://doi.org/10.4236/ojgas.2017.75016

Received: March 30, 2017

Accepted: May 23, 2017

Published: May 26, 2017

Copyright () 2017 by authors and Scientific Research Publishing Inc. This work is licensed under the Creative Commons Attribution International License (CC BY 4.0).

http://creativecommons.org/licenses/by/4.0/

\begin{abstract}
Background/ Aims. Vascular Endothelial Growth Factor (VEGF) has a crucial role in portal hypertension and collateral vessels formation. This study aims to assess urinary VEGF in cirrhotic patients as a predictor of presence of esophageal varices, and variceal bleeding. Settings and Design: 42 cirrhotic patients were randomly selected and classified into 2 groups according to the presence of variceal bleeding. Methods and Material: Urinary VEGF was measured and corrected against urinary creatinine. Platelet count, liver functions, abdominal ultrasonography and upper endoscopy were done. Statistical Analysis Used: Comparison was done by Mann Whitney and Kruskal Wallis tests. Correlation was done using Spearman rank correlation. Multivariable logistic regression was done to identify predictors of variceal bleeding and presence of large varices. Receiver operator characteristic curve (ROC) analysis was used to determine the optimum cut off value of predictors. $R \boldsymbol{e}$ sults and Conclusions. Urinary VEGF was lower in cirrhotic patients with esophageal varices than those without. Low VEGF, low platelet count and splenomegaly were found to be independent predictors of both the presence of large esophageal varices, and variceal bleeding. Cut-off values for platelet count $\leq 166.3 \times 10^{3} / \mu \mathrm{L}$, and corrected VEGF $\leq 59.12 \mathrm{pg} / \mathrm{mg}$ were predictive of large esophageal varices with $93.1 \%, 86.2 \%$ sensitivity and $74.5 \%, 58.2 \%$ specificity respectively. While variceal bleeding could be predicted at a platelet count $\leq 153 \times 10^{3} / \mu \mathrm{L}$, and corrected VEGF $\leq 45.08 \mathrm{pg} / \mathrm{mg}$ with $90.9 \%, 81.8 \%$ sensitivity and $72.6 \%, 59.7 \%$ specificity respectively. The study concludes that urinary VEGF can be used as an alternative to upper endoscopic screening.
\end{abstract}

\section{Keywords}

Liver Cirrhosis, Portal Hypertension, Esophageal Varices, VEGF, Variceal Bleeding 


\section{Introduction}

Cirrhosis is the final outcome of chronic liver disease. Fibrosis, loss of normal architecture and formation of nodules essentially result in portal hypertension due to increased intrahepatic resistance [1]. The most commonly fatal complication of portal hypertension is bleeding esophageal varices [2].

Almost half of patients with liver cirrhosis have got gastro-esophageal varices at first presentation. This percentage increases with progression of liver disease. Variceal bleeding occurs at a rate of 5\% - 15\% per year in untreated subjects, with a mortality rate of $20 \%-30 \%$. Surveillance by upper endoscopy for the presence of varices is therefore recommended at diagnosis of liver cirrhosis to decrease mortality [3]. Follow-up is done according to presence or absence of varices, every 1 - 2 years and 2 - 3 years respectively. Upper endoscopy remains the gold standard for screening; it has its own limitations. It causes a significant burden and cost to endoscopy units and to target patients [4].

Therefore, there is a great need to develop a test to predict the presence of varices by non-endoscopic methods. Such a screening test should be simple, quick, reproducible, and cost effective. Several studies have evaluated the non-invasive markers of oesophageal varices in patients with cirrhosis, such as the platelet count, Fibro Test, spleen size, portal vein diameter, transient elastography of the liver and transient elastography of the spleen [5].

Vascular endothelial growth factor (VEGF) is a glycoprotein that selectively induces endothelial proliferation, angiogenesis, and capillary hyper-permeability and is known as a key regulator of blood vessel growth [6].

Angiogenesis in the splanchnic area is pathogenetic in causing a hyperdynamic circulation and maintaining portal hypertension. This is stimulated by multiple angiogenic factors, the main regulator of which is the vascular endothelial growth factor (VEGF) [7]. Investigations are necessary for assessment of the potential role of VEGF in early prediction of esophageal varices in patients with liver cirrhosis.

The aim of this work was to study the value of VEGF and other variables as platelets count, endoscopic findings and ultrasonographic findings in predicting the risk of upper gastro-intestinal bleeding.

\section{Methods}

\subsection{Population of Study}

This study is conducted on 42 subjects presented to emergency unit, inpatient and outpatient units at Internal Medicine Department of Cairo University Hospitals in the period of time from July, 2015 to December, 2015. The study also included 42 healthy controls, age and sex matched.

All patients with established diagnosis of liver cirrhosis were consecutively included into the study. Patients with other factors known to elevate VEGF levels were excluded. These included patients with hepatocellular carcinoma, or other solid tumors or metastasis, patients with granulomatous disorders including tuberculosis and patients with diabetes or rheumatoid arthritis. 


\subsection{All Patients Were Subjected to the Following}

1) Thorough history taking including personal history, presenting complain (hematemesis or not), medical history (for diabetes, malignancy or any autoimmune disease, cause and duration of cirrhosis) and history of present illness (symptoms of portal hypertension and liver decompensation).

2) Full physical examination including conscious level, vital data (pulse and blood pressure), complexion, ascites, splenomegaly, pleural effusion and lower limb edema.

3) Blood and urinary samples were collected and the following laboratory investigations were done:

- Platelet count.

- Total Vascular endothelial growth factor (VEGF) in urine was done using Quantikine Elisa, Human VEGF Immunoassay Kits (R \& D systems). Urinary VEGF was corrected by adjustment to urinary creatinine.

- Liver enzymes (AST, ALT, ALP, GGT).

- Liver function tests (total protein, albumin, and bilirubin; total and direct, PT, INR).

4) Abdominal ultrasound and upper GI endoscopy were done to all patients.

\subsection{Ethics}

The study was approved by the ethical committee at our faculty. A written informed consent was obtained from all patients.

\subsection{Statistics}

Data were statistically described in terms of mean \pm standard deviation $( \pm S D)$, median and range, or frequencies (number of cases) and percentages when appropriate. Comparison of numerical variables between the study groups was done using Mann Whitney $U$ test for independent samples for comparing 2 groups and Kruskal Wallis test with posthoc multiple 2-group comparisons in comparing more than 2 groups. For comparing categorical data, Chi-square $\left(\chi^{2}\right)$ test was performed. Exact test was used instead when the expected frequency is less than 5. Correlation between various variables was done using Spearman rank correlation equation. Accuracy was represented using the terms sensitivity, and specificity. Receiver operator characteristic (ROC) analysis was used to determine the optimum cut off value for the studied diagnostic markers. $p$ values less than 0.05 was considered statistically significant. All statistical calculations were done using computer program SPSS [8] (Statistical Package for the Social Science; SPSS Inc., Chicago, IL, USA) release 15 for Microsoft Windows (2006).

\section{Results}

Use During the period of study, 42 patients with liver cirrhosis presented to emergency unit, inpatient and outpatient clinic of Internal medicine department of Cairo University with different symptoms as hematemesis, melena, jaundice, encephalopathy, ascites, lower limb edema, bleeding tendency, abdominal pain 
and fever, Table 1. The cases were classified into 2 groups according to the presence or absence of variceal bleeding, Table 2 .

Cases with esophageal varices were furtherly divided into 2 groups according to size of varices, Figure 1.

There was no significant difference between patients with and without varices as regard to age and sex. However, males have higher percentages of varices (83\%) than females (61\%). Table 3 shows Child Pugh classification of studied patients. Table 4 shows laboratory findings of studied groups.

Table 1. Clinical parameters in patient groups.

\begin{tabular}{cccc}
\hline Clinical Data & No Varices $n=11$ & Varices $\mathrm{n}=31$ & $\mathrm{P}$ \\
\hline Hematemesis & 0 & 20 & 0.000 \\
Melena & 5 & 23 & 0.082 \\
Ascites & 10 & 23 & 0.403 \\
LL edema & 6 & 18 & 0.839 \\
Encephalopathy & 3 & 3 & 0.314 \\
Fever & 5 & 14 & 0.987 \\
Jaundice & 6 & 19 & 0.733 \\
Bleeding tendency & 7 & 15 & 0.491 \\
Pleural effusion & 2 & 8 & 0.610 \\
\hline
\end{tabular}

Table 2. Classification of cirrhotic patients with and without varices according to the presence or absence of bleeding.

\begin{tabular}{cccccc}
\hline & Varices & \multicolumn{3}{c}{ No varices } \\
\hline Number $(\%)$ & Bleeding & No bleeding & Number $(\%)$ & Bleeding & No bleeding \\
\hline $31(74 \%)$ & $23(74 \%)$ & $8(26 \%)$ & $11(26 \%)$ & $5(45 \%)$ & $6(55 \%)$ \\
\hline
\end{tabular}

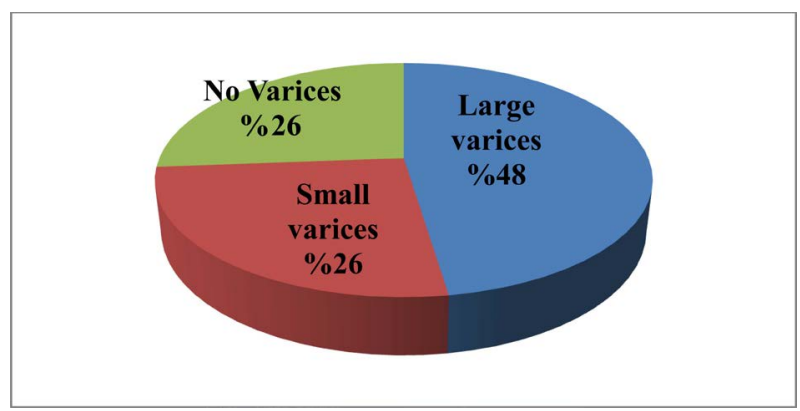

Figure 1. Cirrhotic cases classification according presence of esophageal varices and its size.

Table 3. Child Pugh classification of patients.

\begin{tabular}{cccc}
\hline CHILD Pugh Class & No Varices & Varices & $\mathbf{P}$ \\
\hline CHILD A & 1 & 3 & \\
CHILD B & 6 & 16 & 0.986 \\
CHILD C & 4 & 12 & \\
\hline
\end{tabular}


Table 4. Laboratory parameters among patient groups.

\begin{tabular}{cccccccc}
\hline & \multicolumn{3}{c}{ No Varices } & \multicolumn{3}{c}{ Varices } & P \\
\cline { 2 - 6 } & Median & Max & Min & Median & Max & Min & \\
\hline Platelets count $\times 10^{3} / \mu \mathrm{L}$ & 119 & 337 & 44 & 90 & 182 & 28 & 0.529 \\
AST (U/L) & 55 & 119 & 15 & 61 & 456 & 26 & 0.229 \\
ALT (U/L) & 28 & 53 & 14 & 41 & 349 & 5 & 0.052 \\
ALP (U/L) & 108 & 690 & 62 & 92 & 234 & 52 & 0.258 \\
GGT (U/L) & 130 & 235 & 31 & 73 & 250 & 16 & 0.246 \\
PT (seconds) & 17 & 34.8 & 13 & 17 & 126 & 13 & 0.897 \\
PC (\%) & 61 & 85 & 22 & 57 & 99 & 27 & 0.764 \\
INR & 1.4 & 3.6 & 1.2 & 1.49 & 3.3 & 1 & 0.699 \\
Total protein (g/dl) & 6.6 & 7.9 & 4.7 & 6.3 & 7.9 & 5 & 0.752 \\
Albumin (g/dl) & 2.3 & 4.1 & 1.2 & 2 & 3.4 & 1.1 & 0.455 \\
Total bilirubin (mg/dl) & 1.8 & 14.4 & 0.5 & 1.9 & 13.5 & 0.3 & 0.710 \\
Direct bilirubin (mg/dl) & 1.1 & 9.9 & 0.1 & 0.6 & 13 & 0 & 0.819 \\
VEGF (pg/ml) & 27.5 & 210 & 6 & 17.5 & 203.7 & 6 & 0.775 \\
Urine creat. (mg/dl) & 109.6 & 206.81 & 13.7 & 108.1 & 357.7 & 8.7 & 0.830 \\
VEGF/creat ratio (pg/mg creat.) & 32.02 & 157.3 & 3.7 & 22.65 & 227.6 & 2.9 & 0.368 \\
\hline
\end{tabular}

There were no significant differences as regard to ultrasound findings of splenomegaly and ascites between patients with and without varices.

No correlation between corrected VEGF and ultrasound findings (ascites and splenomegaly) was observed. Also, no correlation between urinary VEGF; VEGF/creatnine ratio and demographic data, clinical, or laboratory parameters was found.

Median corrected urinary VEGF was significantly lower in patients with esophageal varices of any size (22.7) as compared to controls and to patients without varices (99.3 and 69.2, respectively), P-value $=0.001$.

Median corrected urinary VEGF was also significantly lower in patients with large varices (17.7) as compared to patients with small or no varices (69.2), Pvalue $=0.001$.

So VEGF levels were highest in patients without varices, lower in those with small varices and lowest in those with large varices, Figure 2.

Median corrected urinary VEGF was lower in cirrhotic patients with variceal bleeding than those without, and both were lower than controls, Figure 3. Table 5 shows comparison of the median ranks of VEGF in the aforementioned groups.

Multivariable logistic regression showed that platelet count, urinary VEGF level and splenomegaly are independent predictors for the presence of large varices, Table 6. The same factors, platelet count, corrected VEGF level and splenomegaly are also independent predictors for the presence of variceal bleeding, Table 7. 
Receiver operating characteristic (ROC) curve analysis was done to determine the optimum cut off values for platelets and urinary VEGF as predictors of the presence of large esophageal varices as well as variceal bleeding. Figure 4 shows the optimum cut-off values with corresponding sensitivity and specificity. Panel (a) shows the sensitivity and specificity of platelet count as a marker of large eso-

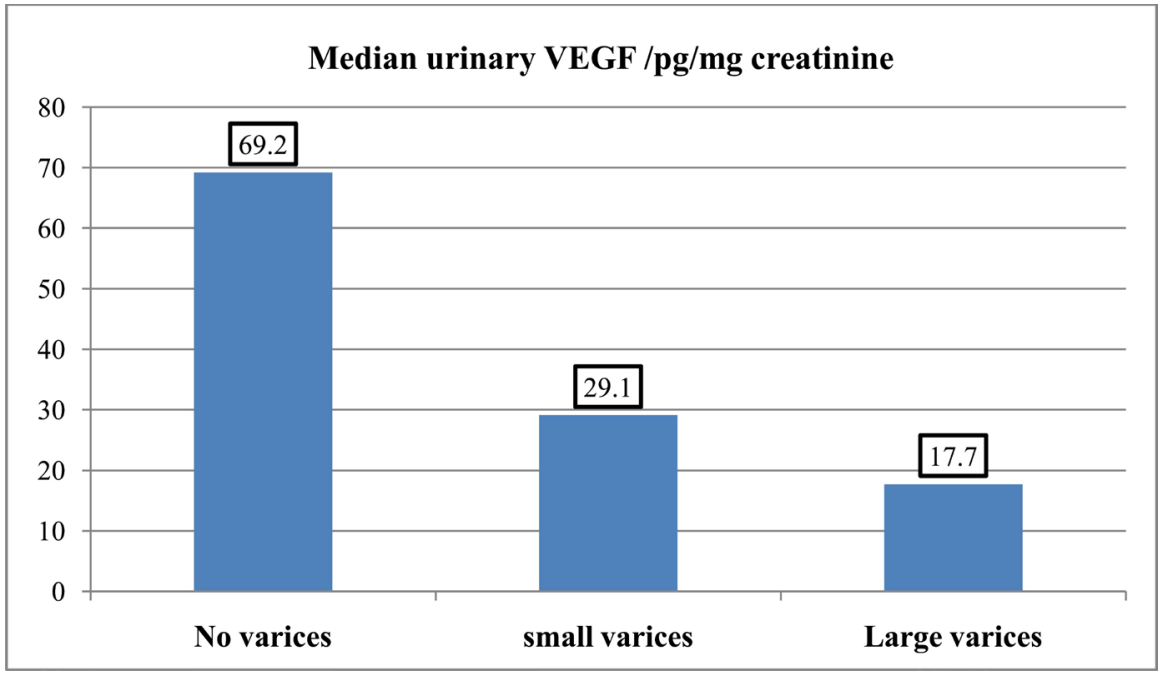

Figure 2. Corrected urinary VEGF in different groups.

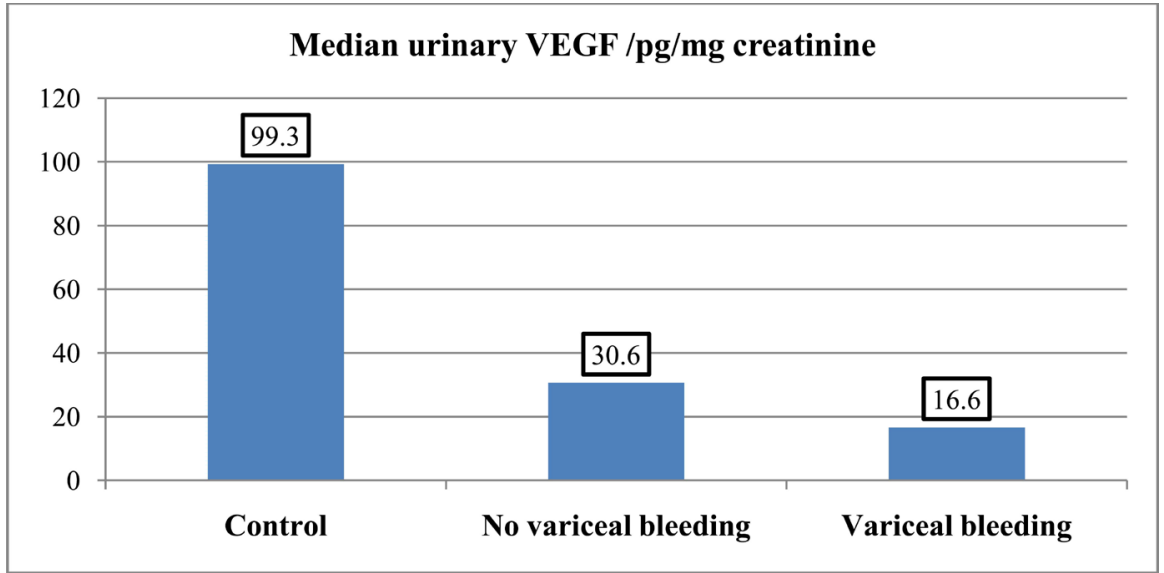

Figure 3. Median corrected urinary VEGF in patients with and without variceal bleeding, as well as healthy controls.

Table 5. Comparison of the mean rank of corrected VEGF among patients with and without variceal bleeding as a well as controls.

\begin{tabular}{ccc}
\hline Group & Mean rank & P \\
\hline Variceal bleeding vs. controls & Control 38.05 & 0.000 \\
& Bleedng 17.75 & \\
No Variceal bleeding vs. controls & Control 37.02 & 0.007 \\
Variceal bleeding vs. no Variceal bleeding & No bleeding 23.86 & \\
& Bleeding 17.95 & 0.074 \\
\hline
\end{tabular}


Table 6. Logistic Regression for predictors of large OV.

\begin{tabular}{|c|c|c|c|c|c|}
\hline & \multirow{2}{*}{ B coefficient } & \multirow{2}{*}{$P$ value } & \multirow{2}{*}{ Odds ratio } & \multicolumn{2}{|c|}{$95 \% \mathrm{CI}$ for OR } \\
\hline & & & & Lower & Upper \\
\hline PLT & -0.011 & 0.007 & 0.989 & 0.981 & 0.997 \\
\hline VEGF/creat & -0.014 & 0.046 & 0.986 & 0.972 & 1.000 \\
\hline splenomegaly & 1.518 & 0.005 & 4.565 & 1.578 & 13.207 \\
\hline
\end{tabular}

Table 7. Logistic Regression for predictors of variceal bleeding.

\begin{tabular}{cccccc}
\hline & \multirow{2}{*}{ B coefficient } & P value & Odds ratio & \multicolumn{2}{c}{$95 \%$ CI for OR } \\
\cline { 5 - 6 } & & & & Lower & Upper \\
\hline PLT & -0.011 & 0.007 & 0.989 & 0.981 & 0.997 \\
VEGF/creat & -0.016 & 0.041 & 0.985 & 0.970 & 0.999 \\
splenomegaly & 1.589 & 0.005 & 4.897 & 1.627 & 14.740 \\
\hline
\end{tabular}

Platelet count as a predictor of large OV

(a)

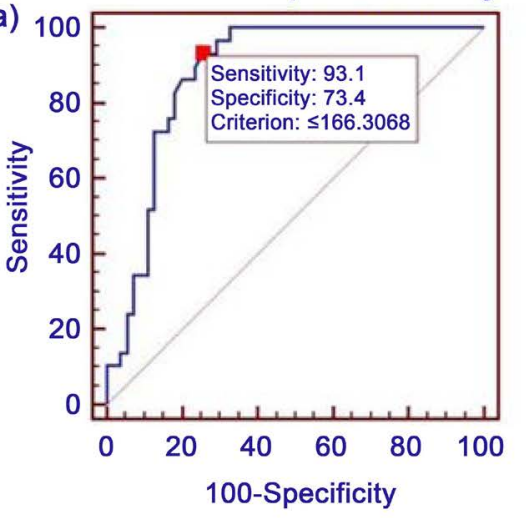

VEGF as a predictor of large OV

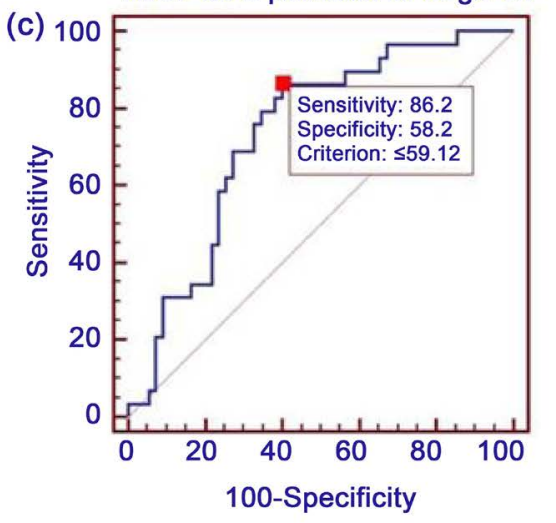

Platelet count as a predictor of variceal bleeding

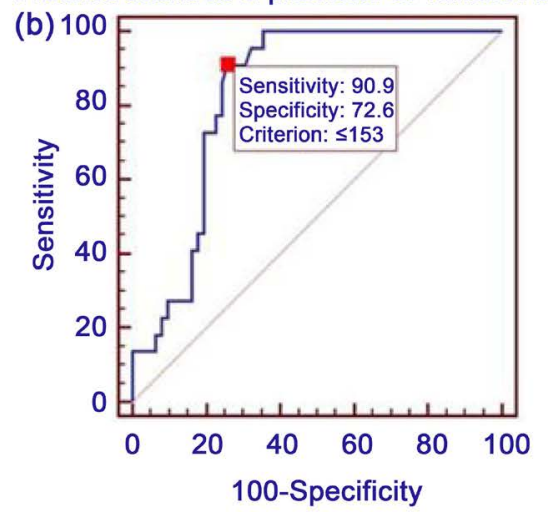

VEGF as a predictor of variceal bleeding

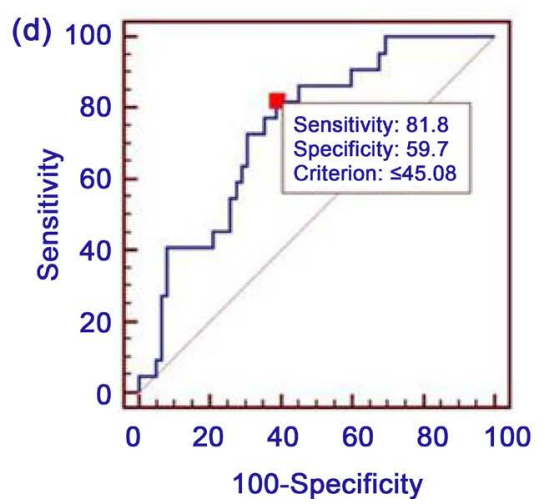

Figure 4. Receiver operating characteristic (ROC) curve analysis showing sensitivity and specificity of platelet count as a marker of large esophageal varices (a), and as a marker of variceal bleeding (b). Receiver operating characteristic (ROC) curve analysis showing sensitivity and specificity of corrected VEGF as a marker of large esophageal varices (c), and as a marker of variceal bleeding $(\mathrm{d})$.

phageal varices. Area under the curve $(A U C)=0.878, P=0.000,95 \%$ CI 0.788 -

0.939 , positive predictive value $65.8 \%$ and negative predictive value $95.3 \%$. Panel 
(b) shows the sensitivity and specificity of platelet count as a marker of variceal bleeding. Area under the curve $(\mathrm{AUC})=0.832, \mathrm{P}=0.000,95 \% \mathrm{CI} 0.735$ to 0.905 , positive predictive value $54 \%$ and negative predictive value of $95.7 \%$.

Panel (c) shows the sensitivity and specificity of urinary VEGF as a marker of large esophageal varices. Area under the curve $(\mathrm{AUC})=0.734, \mathrm{P}=0.000,95 \% \mathrm{CI}$ $0.627-0.825$, positive predictive value $52.1 \%$ and negative predictive value 88.8\%. Panel (d) shows the sensitivity and specificity of urinary VEGF as a marker of variceal bleeding. Area under the curve $(A U C)=0.734, P=0.000$, $95 \%$ CI $0.627-0.825$, positive predictive value $41.8 \%$ and negative predictive value $90.2 \%$.

\section{Discussion}

All patients with liver cirrhosis had significantly lower levels of corrected urinary VEGF than healthy controls. Patients with liver cirrhosis and esophageal varices had significantly lower levels of corrected urinary VEGF than those without. The study also shows that low level of corrected urinary VEGF is significantly associated with increased risk of variceal bleeding among cirrhotic patients.

Several studies had examined plasma, serum and tissue levels of VEGF as well as genetic characters of VEGF in cirrhotic patients. This study is the first to measure urinary VEGF to assess the risk of variceal bleeding in cirrhotic patients. Measuring VEGF in urine, as opposed to serum or plasma, is preferable since urine sample collection is less invasive and simple than drawing blood. In addition, venipuncture activates platelets and release cytokines, including VEGF, which artificially elevates measured VEGF level [9].

None the less, these results correlate well with similar studies measuring serum VEGF: Serum VEGF levels in cirrhotic patients were shown to be significantly lower than those of healthy controls and the mean serum level of VEGF of the cirrhotic patients with portal hypertension was significantly lower than of those without [10]. Other studies also confirmed that serum VEGF levels in patients with cirrhosis were lower than controls [11] [12] [13].

On the other hand, the study done by Nasr et al. in 2013, showed that serum levels of VEGF was significantly increased in cirrhotic patients compared to controls and that the levels of VEGF were positively correlated with portal vein diameter [14]. Other studies also observed increased serum VEGF in liver cirrhosis compared to healthy controls [15] [16] [17].

Another study showed no significant difference between cirrhotic patients with esophageal varices and those without regarding serum VEGF [18].

There are conflicting results concerning the serum VEGF in liver cirrhosis. The precise mechanism triggering VEGF-dependent angiogenesis in portal hypertension remains speculative, but several factors known to occur in portal hypertension, such as tissue hypoxia, cytokines, and mechanical stress have been shown to promote VEGF expression in various tissues and cell types [19]. However, decreased VEGF levels may be related to endothelial dysfunction associated with liver cirrhosis and portal hypertension pathophysiology. VEGF is required 
for reconstruction of hepatic cells and sequentially participates in liver regeneration by facilitating hepatocyte proliferation as well as sinusoidal and LSFC fenestrae number and size normalization [20]. VEGF production is known to be down regulated by several substances including angiostatin, and endostatin. Thus, the low serum VEGF in these patients may be related to the increased activity of these inhibitors [10].

Our study showed as well, that thrombocytopenia is an independent risk factor for presence of large varices as well as their risk for bleeding. This is in agreement with most studies [18] [21] [22]. Cirrhosis is associated with thrombocytopenia and platelet dysfunction due to multifactorial causes occurring simultaneously such as portal hypertension induced splenic pooling and sequestration of platelets from the circulation, portosystemic shunting and gut barrier disruption which result in endotoxaemia with systemic immune activation, antiplatelet antibody production, aberrant fibrinolysis, and activation of coagulation with platelet consumption as well as decreased functional liver mass in cirrhosis which results in lower thrombopoetin levels and platelet underproduction [23].

Our study showed that no significant difference in median urinary VEGF levels was noted among the different Child-Pugh-s classes. This is in accordance with the study done by Assy et al. that clearly indicate that decreased serum VEGF levels did not correlate with the disease severity in patients with liver cirrhosis [10]. Also, the study done by Bai in 2008 showed that the expression of VEGF in esophagus and spleen in patients with PHT was not related to Child-Pugh score [24].

In contrary, the study done by Mathonet et al. in 2006 showed that VEGF was strongly correlated in cirrhotic liver tissues [25]. The highest concentrations of VEGF were observed in patients with advanced stages of liver cirrhosis, which was reflected by a positive correlation with Child-Pugh score specially score C and they suggest that VEGF might be involved in cirrhosis associated angiogenesis as well as portal hypertension [15]. Another study showed that plasma VEGF levels increase with the severity of liver impairment [26] (assessed by the Child-Pugh score and MELD classification).

Our study showed no correlation between VEGF level and clinical presentations as well as no correlation was found between VEGF urinary levels and serum albumin, platelets count and the whole biochemical liver profile. Our findings are consistent with results done by previous research [10] [27]. In another study, plasma VEGF level showed positive correlation with serum bilirubin level and platelet count [17]. Also, in study done by Poon et al. in 2001, there was a positive correlation between the serum VEGF level and platelet count [28]. Platelets release a variety of vasoactive substances, including VEGF, and promote angiogenesis, endothelial permeability, and endothelial growth [17].

Logistic regression was done to test for the value of VEGF and other variables in prediction of the presence of large oesophageal varices, and variceal bleeding. Low platelet count, low VEGF level and splenomegaly were found to be independently associated with variceal bleeding. The same factors i.e. platelet count, 
corrected VEGF level and splenomegaly were found to be independently associated with the presence of large varices. The two outcomes are indeed closely related as $74 \%$ of patients with large varices had at least one episode of variceal bleeding. Therefore, the lower the level of VEGF, the higher the likelihood that a patient with liver cirrhosis will experience variceal bleeding attacks.

These results highlight the association of VEGF with the presence of varices and their tendency to bleed. Furthermore, the regression analysis shows that VEGF may be viewed as a risk factor for variceal bleeding. It may play an actual role in development of large varices and subsequent bleeding. VEGF is a powerful soluble angiogenic factor [29]. It stimulates the production of endothelial progenitor cells (EPO) from the bone marrow into the circulation. These circulating EPOs target injured endothelial surfaces. Homing of EPOs into the sites of endothelial injury occurs where they play a role in repair and regeneration of the endothelium [30]. Thus, low VEGF levels will weaken this healing power and may lead to a higher risk of bleeding.

The impact of low VEGF levels on the risk of variceal bleeding may have multiple mechanisms. In addition to increasing the development of varices and hindering endothelial regeneration, it may play a role in portal hypertension. A study by Nimer et al. have shown significantly lower VEGF levels in patients with portal hypertension patients, with no correlation with Child-Pugh stage [10].

Receiver operating characteristic (ROC) curve analysis was done to test for the predictive ability of each variable showing significant regression value. The relatively high negative predictive value implies that patients with urinary VEGF below the suggested optimum cut-off values are less likely to have large oesophageal varices, and are less likely to bleed as well. This can be put into consideration if prophylactic endoscopy is not desired.

Similarly, platelet count seems to have a stronger negative likelihood prediction for the presence of varices and for occurrence of variceal hemorrhage.

\section{Study Limitations and Future Prospects}

The controversey associated with circulating VEGF levels may be due to the existence of several isoforms (VEGF121, VEGF 165 and VEGF189) [31]. Variability in isoform levels in patients with liver cirrhosis and variceal bleeding is yet to be explored.

\section{Conclusion}

It is concluded from this study that low urinary VEGF/creatinine ratio, thrombocytopenia and splenomegaly are independent risk factors for presence of large esophageal varices as well as their risk for bleeding. Urinary VEGF levels can be combined to platelet count, for screening of liver cirrhosis patients, due to their high sensitivity. As it has a high negative predictive value, it can be used to prevent unneeded endoscopic screening in relevant cases. Urinary VEGF should be viewed as a novel marker for the presence of oesophageal varices and the risk of 
variceal bleeding.

\section{Acknowledgements}

The authors would like to acknowledge our great Kasr Alainy hospital, and its workers, nurses and staff members, for all support and help in this study and throughout our careers.

\section{References}

[1] De Franchis, R. (2010) Revising Consensus in Portal Hypertension: Report of the Baveno, V. Consensus Workshop on Methodology of Diagnosis and Therapy in Portal Hypertension. Journal of Hepatology, 53, 762-768.

[2] Chan, C.C. (2009) Portal-Systemic Collaterals and Angiogenesis. Journal of the Chinese Medical Association, 72, 223-224.

[3] Garcia-Tsao, G., Sanyal, A.J., Grace, N.D. and Carey, W. (2007) Prevention and Management of Gastro-Oesophageal Varices and Variceal Haemorrhage in Cirrhosis. AASLD Practice Guideline. Hepatology, 46, 922-938. https://doi.org/10.1002/hep.21907

[4] Rye, K., Scott, R., Mortimore, G., Lawson, A., Austin, A. and Freeman, J. (2012) Towards Non-Invasive Detection of Oesophageal Varices. International Journal of Hepatology, 1-9. https://doi.org/10.1155/2012/343591

[5] Colecchia, A., Montrone, L., Scaioli, E., Bacchi-Reggiani, M.L., Colli, A., Casazza, G., Schiumerini, R., Turco, L., Di Biase, A.R., Mazzella, G., Marzi, L., Arena, U., Pinzani, M. and Festi, D. (2012) Measurement of Spleen Stiffness to Evaluate Portal Hypertension and the Presence of Esophageal Varices in Patients with HCV-Related Cirrhosis. Gastroenterology, 143, 646-654.

https://doi.org/10.1053/j.gastro.2012.05.035

[6] Yin, Z.H., Liu, X.Y., Huang, R.L. and Ren, S.P. (2005) Expression of TNF- $\alpha$ and VEGF in the Esophagus of Portal Hypertensive Rats. World Journal of Gastroenterology, 11, 1232-1236. https://doi.org/10.3748/wjg.v11.i8.1232

[7] Marques, C., Licks, F., Zattoni, I., Borges, B., de Souza, L.E.R., Marroni, C.A. and Marroni, N.P. (2013) Antioxidant Properties of Glutamine and Its Role in VEGF-Akt Pathways in Portal Hypertension Gastropathy. World Journal of Gastroenterology, 19, 4464-4474. https://doi.org/10.3748/wjg.v19.i28.4464

[8] Statistical Package for the Social Science (2006) Release 15 for Microsoft Windows. SPSS Inc., Chicago.

[9] Hayward, R.M., Kirk, M.J., Sproull, M., Scott, T., Smith, S., Cooley Zgela, T., Crouse, N.S., Citrin, D.E. and Camphausen, K. (2008) Post-Collection, Pre-Measurement Variables Affecting VEGF Levels in Urine Biospecimens. Journal of Cellular and Molecular Medicine, 12, 343-350. https://doi.org/10.1111/j.1582-4934.2007.00135.x

[10] Assy, N., Paizi, M., Gaitini, D., Baruch, Y. and Spira, G. (1999) Clinical Implication of VEGF Serum Levels in Cirrhotic Patients with or without Portal Hypertension. World Journal of Gastroenterology, 5, 296-300.

[11] Kraft, A., Weindel, K., Ochs, A., Marth, C., Zmija, J., Schumacher, P., Unger, C., Marme, D. and Gastl, G. (1999) Vascular Endothelial Growth Factor in the Sera and Effusions of Patients with Malignant and Nonmalignant Disease. Cancer, 85, 178187.

https://doi.org/10.1002/(SICI)1097-0142(19990101)85:1<178::AID-CNCR25>3.0.C $\underline{\mathrm{O} ; 2-7}$ 
[12] Chow, N.H., Hsu, P.I., Lin, X.Z., Yang, H.B., Chan, S.H., Cheng, K.S., Huang, S.M. and Su, I.J. (1997) Expression of Vascular Endothelial Growth Factor in Normal Liver and Hepatocellular Carcinoma: An Immunohistochemical Study. Human Pathology, 28, 698-703.

[13] Akiyoshi, F., Sata, M., Suzuki, H., Uchimura, Y., Mitsuyama, K., Matsuo, K. and Tanikawa, K. (1998) Serum Vascular Endothelial Growth Factor Levels in Various Liver Diseases. Digestive Diseases and Sciences, 43, 41-45. https://doi.org/10.1023/A:1018863718430

[14] Nasr, F.M., Metwaly, A., Abd el Khalik, A, Sabry, A.I., Hassan, M. and Desouky, A.M. (2013) VEGF and PDGF in Liver Cirrhosis and Their Relation to Echocardiographic Parameters and Carotid Intima-Media Thickness. Life Science Journal, 10, 1102-1110.

[15] Abdelmoaty, M.A., Bogdady, A.M., Attia, M.M. and Zaky, N.A. (2009) Circulating Vascular Endothelial Growth Factor and Nitric Oxide in Patients with Liver Cirrhosis: A Possible Association with Liver Function Impairment. Indian Journal of Clinical Biochemistry, 24, 398-403. https://doi.org/10.1007/s12291-009-0071-5

[16] Enjoji, M., Nakamuta, M., Yamaguchi, K., Ohta, S., Kotoh, K., Fukushima, M., et al. (2005) Clinical Significance of Serum Levels of Vascular Endothelial Growth Factor and Its Receptor in Biliary Disease and Carcinoma. World Journal of Gastroenterology, 11, 1167-1171. https://doi.org/10.3748/wjg.v11.i8.1167

[17] Li, C.P., Lee, F.Y., Hwang, S.J., Lu, R.H., Lee, W.P., Chao, Y., et al. (2003) Spider Angiomas in Patients with Liver Cirrhosis: Role of Vascular Endothelial Growth Factor and Basic Fibroblast Growth Factor. World Journal of Gastroenterology, 9, 2832-2835. https://doi.org/10.3748/wjg.v9.i12.2832

[18] Yang, Y.Y., Hou, M.C., Lin, M.W., Chen, P.H., Liao, W.C., Chu, C.J. and Lin, H.C. (2013) Combined Platelet Count with sCD163 and Genetic Variants Optimizes Esophageal Varices Prediction in Cirrhotic Patients. Journal of Gastroenterology and Hepatology, 28, 112-121. https://doi.org/10.1111/j.1440-1746.2012.07245.x

[19] Bosch, J., Abraldes, J.G., Fernández, M. and García-Pagán, J.C. (2010) Hepatic Endothelial Dysfunction and Abnormal Angiogenesis: New Targets in the Treatment of Portal Hypertension. Journal of Hepatology, 53, 558-567.

[20] Lwakiri, Y., Shah, V. and Rockey, D.C. (2014) Vascular Pathobiology in Chronic Liver Disease and Cirrhosis-Current Status and Future Directions. Journal of Hepatology, 61, 912-924.

[21] Ayub, A. (2013) Esophageal Varices, Non Endoscopic Prediction of the Presence. The Professional Medical Journal, 20, 653-660.

[22] Eslam, M., Ampuero, J., Jover, M., Abd-Elhalim, H., Rincon, D., Shatat, M., Camacho, I., Kamal, A., Lo Iacono, O., Nasr, Z., Grande, L., Banares, R., Khattab, M.A. and Romero-Gomez, M. (2013) Predicting Portal Hypertension and Variceal Bleeding Using Noninvasive Measurements of Metabolic Variables. Annals of Hepatology, 12, 420-430.

[23] Tapper, E.B., Robson, S.C. and Malik, R. (2013) Coagulopathy in Cirrhosis: The Role of the Plat1elet in Hemostasis. Journal of Hepatology, 59, 889-890.

[24] Bai, C.Z. (2008) Study of Expression of VEGF, bFGF and TNF- $\alpha$ in Esophagus of Portal Hypertensive Patient and Mechanism of Disruption of Esophageal Varices in Portal Hypertensive Patient. Master's Thesis, General Surgery, Guangxi Medical University.

[25] Mathonnet, M., Descottes, B., Valleix, D., Labrousse, F. and Denizot, Y. (2006) VEGF in Hepatocellular Carcinoma and Surrounding Cirrhotic Liver Tissues. World Journal of Gastroenterology, 12, 830-831. 
https://doi.org/10.3748/wjg.v12.i5.830

[26] Jaroszewicz, J., Januszkiewicz, M., Flisiak, R., et al. (2008) Circulating Vascular Endothelial Growth Factor and Its Soluble Receptors in Patients with Liver Cirrhosis: Possible Association with Hepatic Function Impairment. Cytokine, 44, 14-17.

[27] Mukozu, T., Nagai, H., Matsui, D., Kanekawa, T. and Sumino, Y. (2013) Serum VEGF as a Tumor Marker in Patients with HCV-Related Liver Cirrhosis and Hepatocellular Carcinoma. Anticancer Research, 33, 1013-1021.

[28] Poon, R.T.P., Ng, I.O.L., Lau, C., Zhu, L.X., Yu, W.C., Lo, C.M., Fan, S.T. and Wong, J. (2001) Serum Vascular Endothelial Growth Factor Predicts Venous Invasion in Hepatocellular Carcinoma: A Prospective Study. Annals of Surgery, 233, 227-235. https://doi.org/10.1097/00000658-200102000-00012

[29] Imanishi, T., Tsujioka, H. and Akasaka, T. (2008) Endothelial Progenitor Cells Dysfunction and Senescence: Contribution to Oxidative Stress. Current Cardiology Reviews, 4, 275-286. https://doi.org/10.2174/157340308786349435

[30] Miller-Kasprzak, E. and Jagodzinski, P.P (2007) Endothelial Progenitor Cells as a New Agent Contributing to Vascular Repair. Archivum Immunologiae et Therapia Experimentalis, 55, 247-259. https://doi.org/10.1007/s00005-007-0027-5

[31] Robinson, C.J. and Stringer, S.E. (2001) The Splice Variants of Vascular Endothelial Growth Factor (VEGF) and Their Receptors. Journal of Cell Science, 114, 853-865.

\section{Submit or recommend next manuscript to SCIRP and we will provide best service for you:}

Accepting pre-submission inquiries through Email, Facebook, LinkedIn, Twitter, etc. A wide selection of journals (inclusive of 9 subjects, more than 200 journals) Providing 24-hour high-quality service User-friendly online submission system Fair and swift peer-review system Efficient typesetting and proofreading procedure Display of the result of downloads and visits, as well as the number of cited articles Maximum dissemination of your research work

Submit your manuscript at: http://papersubmission.scirp.org/

Or contact ojgas@scirp.org 